\title{
Superdrainage Reverse-Flow Sural Flap for Distal Leg and Foot Reconstruction: A Method to Overcome Venous Congestion in Diabetic Patients
}

\author{
IBRAHIM S.A. RIHAN, B.Sc.*; AHMED A.A. ALI, M.D.*; MAHMOUD A. HIFNY, M.D.* and \\ SAMIA M.A. SAID, M.D.** \\ The Department of Plastic and Reconstructive Surgery, Faculty of Medicine, South Valley* and Sohag** Universities
}

\begin{abstract}
Background: Soft tissue defect reconstruction in foot and ankle represents a significant challenge for the reconstructive surgeons. The distally based sural flap provides a good option for coverage. Its main disadvantage is the reverse venous flow with frequent venous congestion. Many efforts made to overcome this problem such as super draining the vein through supercharging it to any superficial vein or intermittent drainage by venous cannulation.
\end{abstract}

Patients and Methods: A comparative study was performed on diabetic patients with defects on the foot and ankle at Plastic Surgery Department, Qena University Hospital, from May 2017 to April 2019. Twenty patients were divided into two groups; Group (A): Defects had reconstructed with super drainage reversed sural flap technique (10 cases) and Group (B): Defects had reconstructed with standard reversed sural flap technique (10 cases). They were $14(70 \%)$ males and 6 (30\%) females. Ages of them ranged from 25-65 years old (mean 45 years). Different sites of defect sites had encountered in the study: Heel in 15 cases (75\%), ankle in 3 cases (15\%) and distal leg in 2 cases $(10 \%)$.

Statistical analysis: Data was analyzed using the Statistical Package for Social Sciences (SPSS) version 20. A $p$-value $<0.005$ was considered significant.

Results:

- In Group (A) patients: At the second day post-operative, two cases $(20 \%)$ had slight venous congestion which not relieved by local injection of subcutaneous heparin. A partial flap necrosis occurred only in one of them and the other had complete flap necrosis and flap loss (another flap reconstruction was done). This case also showed wound dehiscence, and graft loss at the pedicle and the donor site areas. All other flaps showed complete healing without complications.

- In Group (B) patient: Venous congestion occurred in seven cases $(70 \%)$ which ended in partial flap necrosis in four cases (40\%) and complete flap necrosis in three cases (30\%). Also, wound dehiscence was reported in the three cases with complete flap loss that underwent secondary surgery for re-stitching. Skin regrafting was performed in 2 (20\%) cases at the pedicle and the donor site area.
The flaps usually healed eventually by $3^{\text {rd }}$ week, but full weight bearing on them postponed up to $6^{\text {th }}$ week and all patients were satisfied with the good functional and aesthetic outcomes.

Conclusion: The distally based the sural flap is a versatile flap for the reconstruction of soft tissue defects of the lower leg and heel. Despite its big problem concerning the reverse venous flow, superdrainage of the lesser saphenous vein either by supercharging or catheterization, provides an effective solution to keep away from venous congestion.

Key Words: Sural flap - Reverse - Flow flap - Superdrainage - Venous congestion.

\section{INTRODUCTION}

Reconstruction of the foot and ankle defects represents a great challenge for the plastic surgeons. This region characterized by lack of tissue availability and relatively poor skin circulation and frequent exposure to trauma. Different methods for coverage involve: Skin grafts, local flaps, distant flaps but their application is limited because of their complications. Free flaps are considered the standard for this region but they need microsurgical experience and longtime procedure, [1].

However, fasciocutaneous flaps; first reported by Ponten in 1981; are excellent option in the repair of these soft-tissue defects, [2]. The distally based sural fasciocutaneous flap was; first introduced by Donski and Fogdestam in 1983; one of the earliest fasciocutaneous flaps used. They described the anatomy, offered a comprehensive description of the surgical procedure and their experience with the flap in three clinical cases, [3]. After this report the sural flap remained largely unmentioned in the literature with only one publication on its anatomical aspects between 1983 and 1992, [4]. 
Masquelet, et al., reintroduced again the sural flap in 1992 with a complete condensed illustration of the related anatomy and the surgical procedure. After the work of Masquelet, et al., the distally based sural fasciocutaneous flap has become a mainstay in the lower leg, heel and foot reconstruction [5]. The main advantage of the sural flap over other flaps of the lower leg is that it does not utilize any of the three major arteries to the distal extremity. The greatest morbidity of the flap is division of the sural nerve, which is usually very well tolerated. The flap is valid in young healthy patients [5].

However, in older patients; especially those with medical comorbidities such as diabetes, neuropathy or peripheral vascular disease; the flap is less predictable. Venous congestion rather than arterial ischemia tends to be a greater problem with this flap especially if designed as an island flap. In these patients, surgical delay procedure or venous supercharging through microvascular venous anastomosis may be considered [6].

In this study, two methods to overcome the venous congestion in the distally based sural flap were applied by supercharging the lesser saphenous vein through venous anastomosis to a superficial vein in the foot or by venous cannulation of the proximal stump of the lesser saphenous vein.

\section{PATIENTS AND METHODS}

\section{Demographic data:}

A comparative study was performed on diabetic patients with defects on the distal third leg and foot at Plastic Surgery Department, Qena University Hospital, from May 2017 to April 2019 (two years duration). Twenty patients enrolled into the study and were divided into two groups; Group (A): Defects had reconstructed with super drainage reversed sural flap technique (10 cases) and Group (B): Defects had reconstructed with standard reversed sural flap technique (10 cases).

Both sexes were reported: 14 (70\%) males and $6(30 \%)$ females; all from our outpatient clinic. Ages ranged from 25-65 years old (mean 45 years). Main etiological factor was diabetes with additional factor like neuropathy in 11 cases and ischemia in 9 cases. Different sites of defect had encountered: The heel in 15 cases $(75 \%)$, the ankle in 3 cases $(15 \%)$ and the distal third leg in 2 cases $(10 \%)$.

All patients with intact superficial and deep venous system were included in the study. Patients with chronic venous insufficiency and where the zone of injury extends to the area of peroneal perforators were excluded from the study. Doppler ultrasound and venography had done before selection of the cases to insure the patency of peroneal perforators and the venous system respectively. Blood sugar level monitoring was mandatory before surgery, and so controlled diabetic patients were eligible for operation.

Every patient had data sheet with the following parameters: Age, sex, etiology of the defect, site and size of the defect, flap technique, and flap dimensions, donor site closure and complications. Informed consent was obtained from all patients. The study was approved by the ethical committee in our faculty for research in human studies.

\section{Pre-operative preparation:}

Procedures had performed under spinal anesthesia with all patients in the prone position. A handheld Doppler was used before flap marking to predetermine the perforators of the peroneal artery. Perioperative I.V. antibiotics ( $3^{\text {rd }}$ generation Cephalosporins) were injected. For easily dissection, application of pneumatic tourniquet after exsanguination and the use of (3.5X) loupe magnifications were used.

\section{Marking the flap:}

As in the standard reversed sural flap technique, firstly; the defect was debrided. Average size of the defects ranged from $(2 \times 2.5 \mathrm{~cm})$ to $(5 \times 6 \mathrm{~cm})$. Then; the flap was marked with a line drawn from a point midway between the Achilles tendon and the lateral malleolus to the midline between two heads of the gastrocnemius muscle. This marks the pathway of sural nerve and short saphenous vein. After that; the larger peroneal perforator detected by handheld Doppler was marked, which is often located approximately $5 \mathrm{~cm}$ superior to the tip of the lateral malleolus.

\section{Surgical technique:}

A template of the defect was drawn and the flap outlined and centered over line that marked the sural nerve. Average size of flaps drawn ranged from $(5 \times 6 \mathrm{~cm})$ to $(10 \times 14 \mathrm{~cm})$ with mean $(7.5 \mathrm{X}$ $10 \mathrm{~cm})$. Firstly, the proximal border of the flap is incised. Then, the sural nerve and lesser saphenous vein were identified at the mid-calf supra-fascially. In the superdrainage technique, the sural nerve, superficial median sural artery and lesser saphenous vein were divided and ligated, with preservation of long proximal vein stump which included within the flap. The dissection was then resumed distally in the subfascial plane. All musculocutaneous perforators emerged from the gastrocnemius muscle were recognized and cauterized. Distally; a narrow 
longitudinal band of the fascia and subcutaneous fascial pedicle, which involved the sural nerve and lesser saphenous vein, elevated with a width of $4 \mathrm{~cm}$ to protect the pedicle.

Laterally, the dissection was up to medial border of the fibula and medially to the lateral border of the Achilles tendon. The dissection discontinued at the pivot point which is $5 \mathrm{~cm}$ proximal to the lateral malleolus where perforators from the peroneal artery connect with the vascular plexus. Division of the skin island between the donor site and the defect had done to avoid the risk of compression of the pedicle (no subcutaneous tunnel). After the flap was inset into the defect, the tourniquet was deflated and hemostasis had achieved.

In the superdrainage technique, end-to-end anastomosis for supercharging had performed be- tween the free end of long stump of the lesser saphenous vein and a superficial leg or foot vein as a recipient vein; that found close to the defect; under (3.5X) loupe magnification in six cases using $9 / 0$ nylon sutures. Venous cannulation was carried out in four cases with 20 or 24 gauge cannula according to the caliber of the vein. Intermittent drainage of the vein was done hourly in the first six hours (golden hours), every two hours in the next 18 hours at the first day and then every 4 hourly at the next 3 days.

The pedicle and the donor site were covered with a split thickness skin graft. A well-padded dressing had applied making sure that there is no compression on the pedicle with a window left exposed for observation, (Tables 1,2) shows the data of the two groups of the patients.

Table (1): Group (A): Patients with superdrainage reverse flow sural flap technique.

\begin{tabular}{|c|c|c|c|c|c|c|c|}
\hline No. & $\begin{array}{l}\text { Age } \\
\text { (yrs.) }\end{array}$ & Sex & Etiology & $\begin{array}{l}\text { Site and size } \\
\text { of defect }\end{array}$ & Technique of flab & Flab size & $\begin{array}{l}\text { Follow-up } \\
\text { (month) }\end{array}$ \\
\hline 1 & 42 & M & Diabetes + neuropathy & $\begin{array}{l}\text { Right heel } \\
3 \mathrm{X} 4 \mathrm{~cm}\end{array}$ & Supercharged with superficial vein in foot & $5 \times 6 \mathrm{~cm}$ & 7 \\
\hline 2 & 25 & M & Diabetes + ischemia & $\begin{array}{l}\text { Left heel } \\
2 \times 2.5 \mathrm{~cm}\end{array}$ & Venous Cannulation with 20 gauge cannula & $3 \times 4 \mathrm{~cm}$ & 8 \\
\hline 3 & 62 & $\mathrm{~F}$ & Diabetes + neuropathy & $\begin{array}{l}\text { Right heel } \\
2.5 \times 3 \mathrm{~cm}\end{array}$ & Supercharged with superficial vein in foot & $3 \times 4 \mathrm{~cm}$ & 6 \\
\hline 4 & 39 & M & Diabetes + neuropathy & $\begin{array}{l}\text { Left ankle } \\
4 \times 5 \mathrm{~cm}\end{array}$ & Venous Cannulation with 24 gauge cannula & $5 \times 5 \mathrm{~cm}$ & 12 \\
\hline 5 & 45 & $\mathrm{~F}$ & Diabetes + ischemia & $\begin{array}{l}\text { Left heel } \\
5 \times 6 \mathrm{~cm}\end{array}$ & Supercharged with superficial vein in foot & $6 \times 7 \mathrm{~cm}$ & 10 \\
\hline 6 & 28 & M & Diabetes + neuropathy & $\begin{array}{l}\text { Right heel } \\
3 \mathrm{X} 4 \mathrm{~cm}\end{array}$ & Venous Cannulation with 20 gauge cannula & $5 \times 6 \mathrm{~cm}$ & 7 \\
\hline 7 & 40 & M & Diabetes + neuropathy & $\begin{array}{l}\text { Right ankle } \\
4 \times 5 \mathrm{~cm}\end{array}$ & Supercharged with superficial vein in foot & $3 \times 4 \mathrm{~cm}$ & 11 \\
\hline 8 & 60 & M & Diabetes + ischemia & $\begin{array}{l}\text { Left heel } \\
3 \times 4 \mathrm{~cm}\end{array}$ & Venous Cannulation with 24 gauge cannula & $5 \times 5 \mathrm{~cm}$ & 14 \\
\hline 9 & 53 & $\mathrm{~F}$ & Diabetes + neuropathy & $\begin{array}{l}\text { Right heel } \\
2.5 \times 4 \mathrm{~cm}\end{array}$ & Supercharged with superficial vein in foot & $6 \times 7 \mathrm{~cm}$ & 18 \\
\hline 10 & 36 & M & Diabetes + ischemia & $\begin{array}{l}\text { Distal left leg } \\
5.5 \times 4.5 \mathrm{~cm}\end{array}$ & Supercharged with superficial vein in foot & $5 \times 6 \mathrm{~cm}$ & 15 \\
\hline
\end{tabular}

Table (2): Group (B): Patients with standard reverse flow sural flap technique.

\begin{tabular}{|c|c|c|c|c|c|c|c|}
\hline No. & $\begin{array}{l}\text { Age } \\
\text { (yrs.) }\end{array}$ & Sex & Etiology & Site and size of defect & $\begin{array}{l}\text { Technique } \\
\text { of flab }\end{array}$ & Flab size & $\begin{array}{l}\text { Follow-up } \\
\text { (month) }\end{array}$ \\
\hline 1 & 35 & $\mathrm{~F}$ & Diabetes + neuropathy & Left heel $3 \times 4 \mathrm{~cm}$ & Standard & $5 \times 6 \mathrm{~cm}$ & 11 \\
\hline 2 & 48 & M & Diabetes + ischemia & Right heel $2.5 \times 4 \mathrm{~cm}$ & Standard & $5 \times 5 \mathrm{~cm}$ & 15 \\
\hline 3 & 42 & M & Diabetes + neuropathy & Left heel 3 X 4cm & Standard & $6 \times 7 \mathrm{~cm}$ & 9 \\
\hline 4 & 50 & M & Diabetes + neuropathy & Left heel $2 \times 2.5 \mathrm{~cm}$ & Standard & $5 \times 6 \mathrm{~cm}$ & 12 \\
\hline 5 & 47 & $\mathrm{~F}$ & Diabetes + ischemia & Right heel $2.5 \times 3 \mathrm{~cm}$ & Standard & $6 \times 7 \mathrm{~cm}$ & 14 \\
\hline 6 & 56 & M & Diabetes + ischemia & Left heel 5 X $6 \mathrm{~cm}$ & Standard & $5 \times 6 \mathrm{~cm}$ & 12 \\
\hline 7 & 29 & M & Diabetes + neuropathy & Distal right leg $5 \times 6 \mathrm{~cm}$ & Standard & $3 \times 4 \mathrm{~cm}$ & 8 \\
\hline 8 & 34 & $\mathrm{~F}$ & Diabetes + ischemia & Right ankle 4 X 5cm & Standard & $4 \times 5 \mathrm{~cm}$ & 9 \\
\hline 9 & 65 & M & Diabetes + ischemia & Left heel $3 \times 4 \mathrm{~cm}$ & Standard & $5 \times 5 \mathrm{~cm}$ & 11 \\
\hline 10 & 45 & M & Diabetes + neuropathy & Left heel $2 \times 4 \mathrm{~cm}$ & Standard & $6 \times 7 \mathrm{~cm}$ & 10 \\
\hline
\end{tabular}




\section{Follow-up:}

A leg elevation is maintained at $45^{\circ}$ to enhance the venous return. The dressing is changed on $3^{\text {th }}$ post-operative day. All patients were followed-up for a period from 6 to 18 months (mean=12 months). The flaps usually healed eventually by $3^{\text {rd }}$ week, but full weight bearing on them postponed up to $6^{\text {th }}$ week and all patients were satisfied with the good functional and aesthetic outcomes.

\section{Statistical analysis:}

Data was analyzed using the Statistical Package for Social Sciences (SPSS) version 20. A $p$-value $<0.005$ was considered significant.

\section{RESULTS}

In Group (A) patients with super drainage technique: In the second day postoperatively, two cases $(20 \%)$ had venous congestion (cases no. 5 and no. 8). This congestion was not relived by local subcutaneous injection of heparin and ended with partial flap necrosis at the fifth day, then one of the two flaps (no. 8) had complete flap necrosis and flap loss (another flap reconstruction was done). This case also showed wound dehiscence, and graft loss at the pedicle and the donor site areas. All other flaps showed complete healing without complications.

In Group (B) patients with standard technique: Venous congestion occurred in seven cases (70\%) which ended in partial flap necrosis in four cases $(40 \%)$ cases (no. 2, 3, 6 and 8) and complete flap necrosis in three cases (30\%) cases (no. 1, 5 and 9). Also, wound dehiscence was reported in the three cases with complete flap loss that underwent
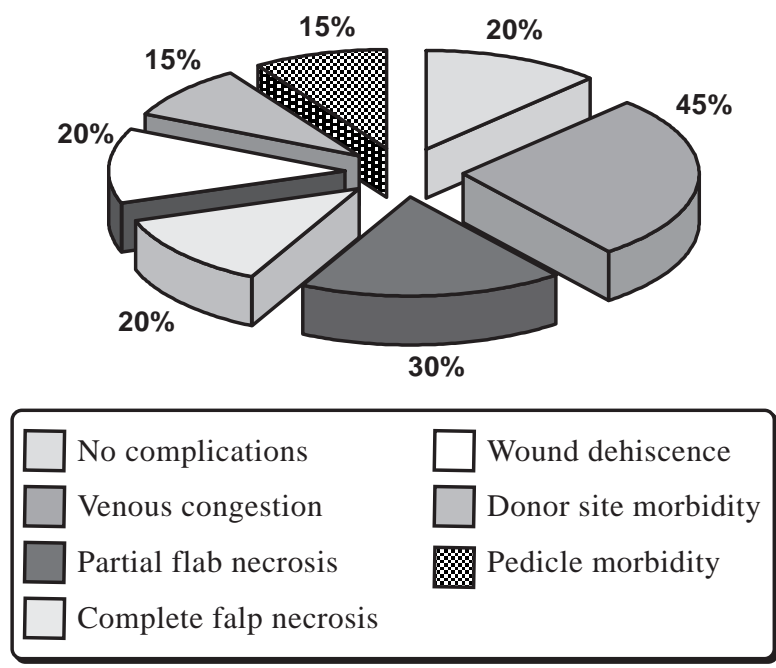

Fig. (1): Percentage of complications in both techniques. secondary surgery for re-stitching. Skin regrafting was performed in $2(20 \%)$ cases at the pedicle and the donor site area.

Comparison between these groups was statistically significance for the above mentioned differences $(p<0.005)$, Figs. $(1,2)$, and (Table 3$)$ shows the rate of complication between both techniques.

Table (3): Rate of complication between superdrainage and standard technique.

\begin{tabular}{|c|c|c|c|}
\hline \multirow{2}{*}{ Complications } & \multicolumn{2}{|c|}{ Group } & \multirow{2}{*}{$\begin{array}{c}p- \\
\text { value }\end{array}$} \\
\hline & Group A & Group B & \\
\hline \multicolumn{4}{|c|}{ 1- No complications: } \\
\hline Count & 2 & 0 & $0.005 \mathrm{~s}$ \\
\hline$\%$ & $20.0 \%$ & $.0 \%$ & \\
\hline \multicolumn{4}{|c|}{ 2- Venous congestion: } \\
\hline Count & 2 & 7 & \\
\hline$\%$ & $20.0 \%$ & $70 \%$ & \\
\hline \multicolumn{4}{|c|}{ 3- Partial flap necrosis: } \\
\hline Count & 2 & 4 & \\
\hline$\%$ & $20.0 \%$ & $40 \%$ & \\
\hline \multicolumn{4}{|c|}{ 4- Complete flap necrosis: } \\
\hline Count & 1 & 3 & \\
\hline$\%$ & $10.0 \%$ & $30 \%$ & \\
\hline \multicolumn{4}{|c|}{ 5- Wound dehiscence: } \\
\hline Count & 1 & 3 & \\
\hline$\%$ & $10.0 \%$ & $30 \%$ & \\
\hline \multicolumn{4}{|c|}{ 6- Donor site morbidity: } \\
\hline Count & 1 & 2 & \\
\hline$\%$ & $10.0 \%$ & $20 \%$ & \\
\hline \multicolumn{4}{|c|}{ 7- Pedicle morbidity: } \\
\hline Count & 1 & 2 & \\
\hline$\%$ & $10.0 \%$ & $20 \%$ & \\
\hline
\end{tabular}
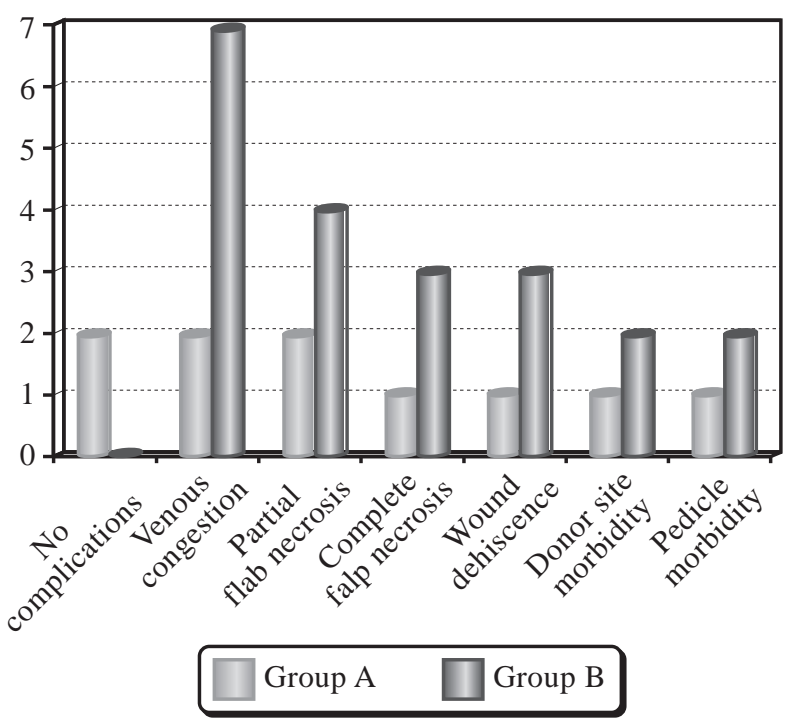

Fig. (2): Rate of complications in both techniques. 


\section{Case presentations:}

Case 1: (Patient no. 1): A 42-years-old man with chronic ulcer right heel. Supercharged sural flap with superficial vein in the foot was done. There were no complications; the patient began walking with silicon heel after 8 weeks with no complications, Fig. (3).
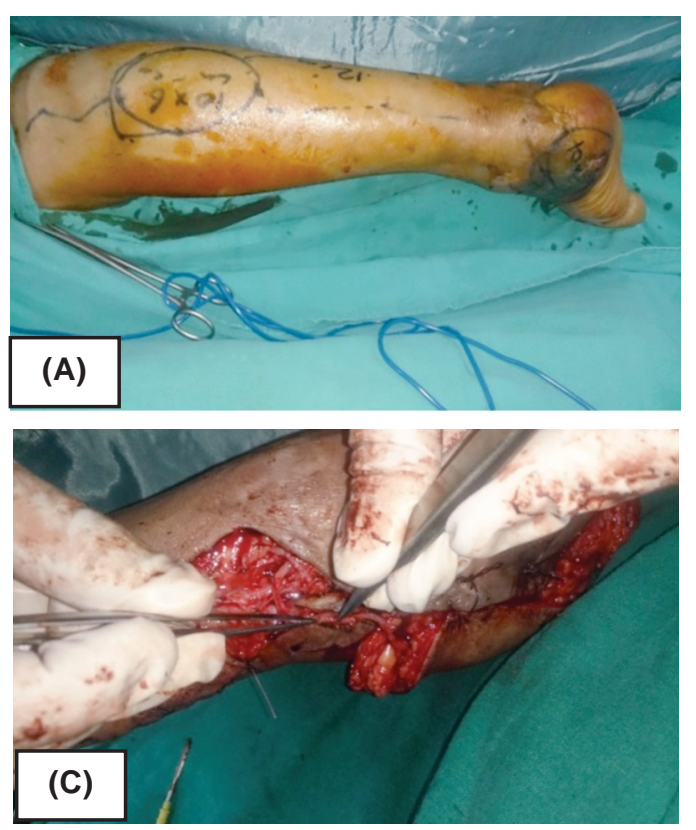

Fig. (3): (A) Pre-operative marking of the flap. (B) Shows the free proximal end of short saphenous vein and superficial vein. (C) Shows the anastomosis between the two veins. (D) Post-operative of the flap after 3 months.
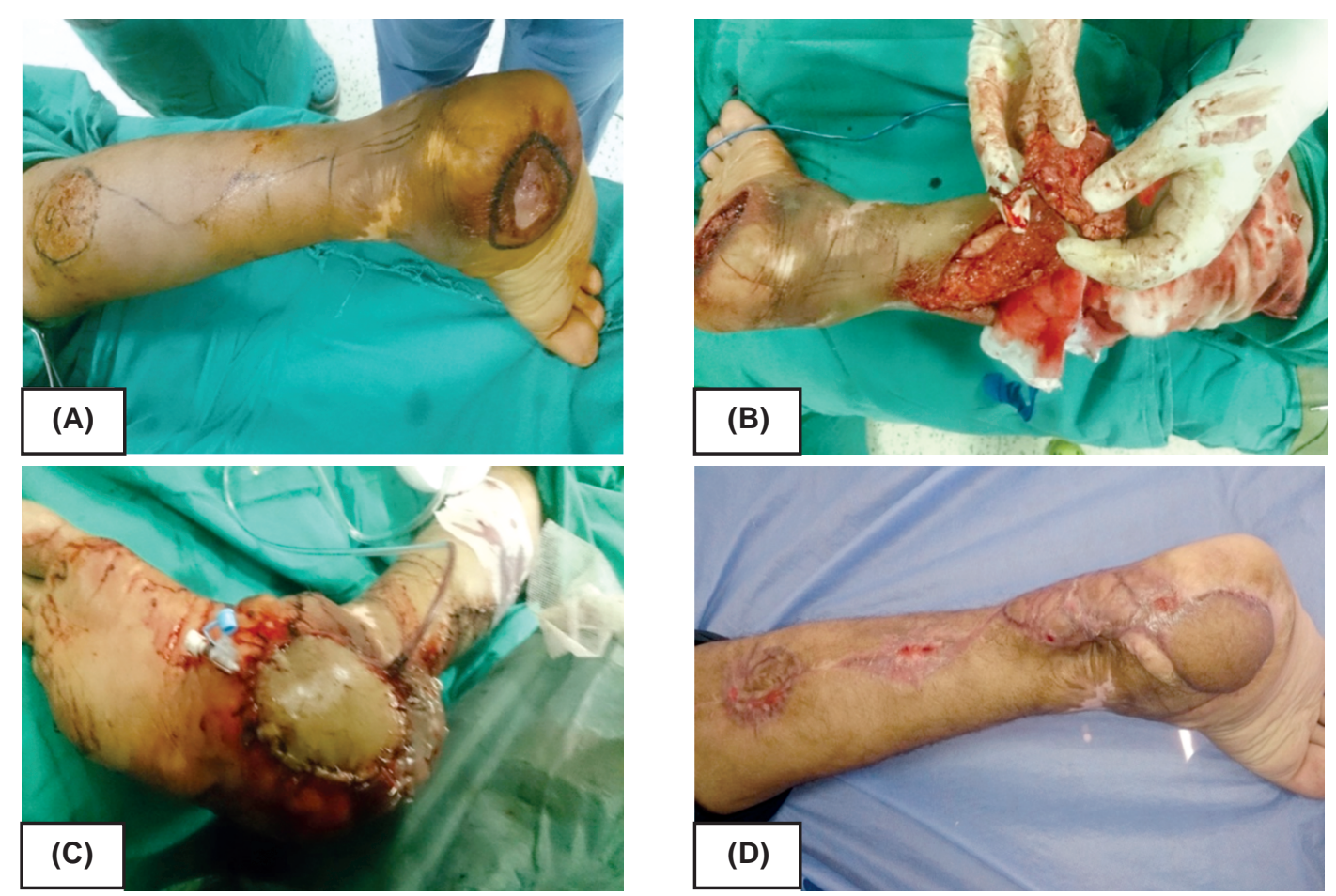

Fig. (4): (A) Pre-operative marking of the flap. (B) Shows the long proximal stump of short saphenous vein. (C) Cannulation of the vein (D) Post-operative after 3 months.

Case 2: (Patient no. 6): A 28-years-old male had chronic trophic ulcer at right heel. Sural flap with lesser saphenous cannulation was done. Normal flap monitoring signs during follow-up and flap healed within 4 weeks. There were no complications and patient began walking with silicon heel after 7 weeks with no complications, Fig. (4).
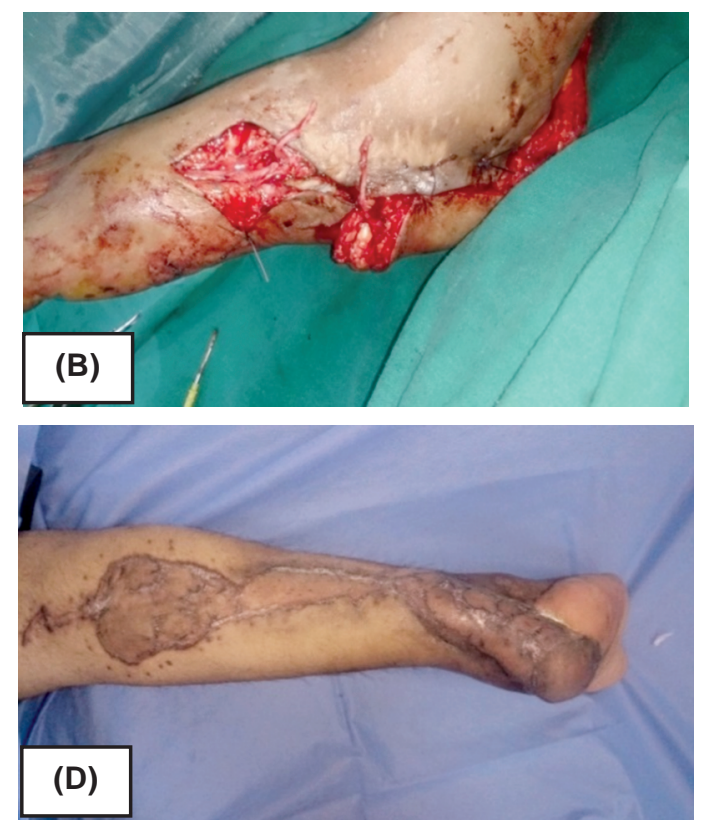

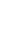

. 


\section{DISCUSSION}

The distally based sural artery fasciocutaneous flap has become a workhorse in the soft tissue reconstruction of difficult defects in the lower leg, ankle, and foot. Its success in appropriately selected patients is well documented. However, complications such as venous congestion, flap necrosis, and other complications are still significant [7].

The largest published data to critically review the flap complication rate found that an overall complication rate of 59\% (41 of 70 flaps) [8] age; greater than 40 years; and significant medical comorbidities were both significant risk factors for complications. Specific medical comorbidities that were found to be risk factors included diabetes, peripheral arterial disease and venous insufficiency [8].

Another more recent review by Parrett et al., [9] found an overall complication rate of 50\% (29 out of 58 flaps). Risk factors for these complications were the same: Older age, history of smoking, obesity, diabetes, and peripheral arterial disease [9].

Many modifications have been performed to achieve the safe and reliable flaps from reconstructing the distal leg. Baumeister et al., [8] proposed the use of a sural flap "delay" procedure in an effort to diminish the risk of flap failure. Dragu et al., [10] performed a supercharged venous anastomosis of the proximal end stump of the sural flap vein (lesser saphenous) with a subcutaneous vein found locally in the recipient site to reduce the risk of venous congestion.

Yao et al., [11] included the distal part of the peroneal artery and its cutaneous branches in the sural flap to augment the supply of the flap. AlQattan [12] harvested a midline "cuff " of gastrocnemius muscle containing the buried sural pedicle with the flap. This modification maintains a "mesenteric" connection between the sural pedicle and the overlying fascia in the proximal part of the leg.

Ayyappan and Chadha [13] also named the vascular plexus around the sural nerve, sural artery, and lesser saphenous vein between the 2 heads of the gastrocnemius muscle mesentery-like structure, which were kept intact in their flaps. The large reversed sural fasciocutaneous flaps with sites extending beyond the proximal one third of the leg were harvested successfully.

Other modifications included a wider-thanusual pedicle, subcutaneous transposition with the aid of soft tissue expander, the inclusion of subcu- taneous tissue in the pedicle, and exteriorizing the pedicle [14].

In this study, a superdrainage technique for the short saphenous vein had performed to overcome venous congestion. This superdrainage was achieved by two methods: The first one by supercharging the proximal stump of the short saphenous vein to a superficial vein in the foot with microvascular anastomosis in six cases and the other method through intermittent drainage of the proximal stump of the vein by using venous cannulas in four cases.

Although this study enrolled high risk patients; with diabetes, neuropathy and ischemic vascular disease, this superdrainage modification had been helpful in these patients to guarantee against venous congestion.

By supercharging the sural flap, the venous load; having also normal reverse venous drainage through the suprafascial venous network in the pedicle; decreases and the venous drainage associated with the angulation or compression of the pedicle; that leading to lack of reverse venous flow; is only maintained antegradely because the lesser saphenous vein is less affected than the suprafascial venous network. This also allowed harvesting flaps of large sizes [15].

In this technique of supercharging, a superficial vein in satisfactory size around the recipient site was sufficient, and a major vein in the leg was not sacrificed. Thus, the method may be applied in cases with peripheral venous insufficiency in the lower limb comfortably. Also, microsurgical experience was not required for end-to end anastomoses. So, this modification can be easily practiced and taught.

This modification greatly improves the venous return as it provides an alternative pathway for venous drainage that blocked by venous valves. The unique disadvantage of this modification was an increase in procedure time of 30 minutes on average. Sometimes, it may be difficult to find a satisfactory recipient vein with sufficient caliber.

Another method to overcome venous congestion in this study was venous cannulation of the proximal stump of the lesser saphenous vein with large pore cannula (20/24 gauges). This method had an effective way for intermittent venous drainage of the vein and prevented the occurrence of congestion. Post-operative close follow-up was planned for these cases to drain the vein through the cannula every one hour in the first six golden hours then 
every two hours in the next 18 hours at the first day and then every 4 hourly at the next 3 days.

Rate of complication in cases superdrainage technique was fewer than cases reconstructed with standard flap technique, there were only two cases that had slight venous congestion This congestion was not relived by local subcutaneous injection of heparin and ended with partial flap necrosis at the fifth day, then one of the two flaps (no. 8) had complete flap necrosis and flap loss (another flap reconstruction was done). All other flaps showed complete healing without complications. In contrary to cases reconstructed with standard flap technique, venous congestion occurred in seven cases which ended in partial flap necrosis in four of them and complete flap necrosis in three cases. Wound dehiscence reported in three cases that underwent secondary surgery for re-stitching and skin regrafting was performed in two cases at the pedicle and the donor site area.

Dragu et al., [10] recommended supercharging a proximal end of lesser saphenous vein to a subcutaneous vein around the defect if the venous congestion of the flap was diagnosed during operation. Tan et al., [15] attempted to increase the venous outflow by performing an anastomosis between the stump of the lesser saphenous vein at the proximal end of the flap and a superficial vein in the leg but claimed that such veins could not always be identified.

Wong and Tan [16] proposed that harvesting the reverse sural flap with an extra length of lesser saphenous vein for supercharging or intermittent drainage to overcome flap congestion could enhance the flap success rate. Loonen et al., [17] also advised that if venous congestion occurred during operation or even postoperatively, anastomosing the lesser saphenous vein to other subcutaneous veins found locally in the defect site may increase venous return.

\section{Conclusion:}

In this study venous super-drainage could dramatically reduce the incidence of venous congestion by augmenting the venous output, thereby increasing flap reliability and allowing for larger flap sizes with lower rates of complications related to venous congestion.

\section{REFERENCES}

1- Vergara-Amador E.: Distally-based superficial sural neurocutaneous flap for reconstruction of the ankle and foot in children. J. Plast. Reconstr. Aesthet. Surg., 62: 1087, 2009.
2- Pontén B.: The fasciocutaneous flap: Its use in soft tissue defects of the lower leg. Br. J. Plast. Surg., 34: 215, 1981.

3- Donski P.K. and Fogdestam I.: Distally based fasciocutaneous flap from the sural region: A preliminary report. Scand. J. Plast. Reconstr. Surg., 17: 191, 1983.

4- Le Huec J.C., Midy D., Chauveaux D., et al.: Anatomic basis of the sural fascio-cutaneous flap: Surgical applications. Surg. Radiol. Anat., 10: 5, 1988.

5- Masquelet A.C., Romana M.C. and Wolf G.: Skin island flaps supplied by the vascular axis of the sensitive superficial nerves: Anatomic study and clinical experience. Plast. Reconstr. Surg., 89: 1115, 1992.

6- Follmar Keith, E.BA.; Baccarani Alessio, M.D.; Baumeister Steffen, P.M.D.; Levin L. Scott, M.D.; Erdmann Detlev, M.D., Ph.D.: The Distally Based Sural Flap. Plastic and Reconstructive Surgery: 119 (6): 138-48, May 2007.

7- Keith E. Follmar, M.D.* and Detlev Erdmann, M.D., Ph.D., MHScw: The Distally Based Sural Flap Techniques in Foot \& Ankle Surgery: 12 (2), June 2013.

8- Baumeister S.P., Spierer R., Erdmann D., et al.: A realistic complication analysis of 70 sural artery flaps in a multimorbid patient group. Plast. Reconstr. Surg., 112: 129, 2003.

9- Parrett B.M., Pribaz J.J., Matros E., et al.: Risk analysis for the reverse sural fasciocutaneous flap in distal leg reconstruction. Plast. Reconstr. Surg., 123: 1499, 2009.

10- Dragu A., Bach A.D., Kneser U., et al.: Two easy and simple modifications when using a distally based sural flap to reduce the risk of venous congestion. Plast. Reconstr. Surg., 122: 683-4, 2008.

11- Yao S., Zhang F., Pan J., et al.: Modified distally based sural nerve flaps in acute traumatic forefeet reconstructions. Ann. Plast. Surg., 63: 77-80, 2009.

12- Al-Qattan M.M.: A modified technique for harvesting the reverse sural artery flap from the upper part of the leg: Inclusion of a gastrocnemius muscle "cuff "around the sural pedicle. Ann. Plast. Surg., 47: 269-74, 2001.

13- Ayyappan T. and Chadha A.: Super sural neurofasciocutaneous flaps in acute traumatic heel reconstructions. Plast. Reconstr. Surg., 109: 2307-13, 2002.

14- Afifi A.M., Mahboub T.A., Losee J.E., et al.: The reverse sural flap: Modifications to improve efficacy in foot and ankle reconstruction. Ann. Plast. Surg., 61: 430-6, 2008.

15- Tan O., Atik B. and Bekerecioglu M.: Supercharged reverse-flow sural flap: A new modification increasing the reliability of the flap. Microsurgery, 25: 36-43, 2005.

16- Wong C.H. and Tan B.K.: Intermittent short saphenous vein phlebotomy: An effective way of relieving venous congestion in the distally based sural artery flap. Ann. Plast. Surg., 58: 303-7, Mar. 2007.

17- Loonen M.P., Kon M. and Schuurman A.H.: Distally based sural flap modifications. Ann. Plast. Surg., 64: $128,2010$. 